\title{
Editorial: Latest advances from India
}

\section{Prakash P. Wadgaonkar PhD}

Chief Scientist, Polymers and Advanced Materials Laboratory, Polymer Science and Engineering Division, CSIR-National Chemical Laboratory, Pune, India

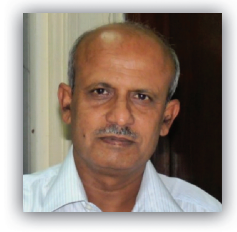

Welcome to this themed issue of Green Materials covering the latest advances from India. A lot of attention is being paid towards development of sustainable materials in both industrial and academic laboratories worldwide. The Indian researchers working in various universities and government laboratories have made notable contributions to the area of green materials in general and polymers in particular.

This themed issue is dedicated to the topic of sustainable polymeric materials and comprises the following contributions.

The paper by Krishnamurthy et al. ${ }^{1}$ describes the 'click' polymerization reaction on functionalized single-walled carbon nanotubes. The wettability measurements showed the superhydrophobic characteristics of the polymer on different surfaces, presumably due to the 'lotus effect'. Such materials are potentially useful in designing water-repellent leather for allweather comfort.

The second article by Pentela et $a l^{2}$ deals with a comparative study of the pH-responsive nature of microcapsules made with poly(methacrylic acid) and fullerenol or graphene oxide. The developed strategy allows fine-tuning of release of the encapsulated materials like drugs or nutrients by tuning the $\mathrm{pH}$. Such designer microcapsules using carbon nanomaterials are important for targeted drug delivery applications.

The article by Chikkali and co-workers ${ }^{3}$ presents an interesting approach for utilization of chemicals derived from biomass as renewable building blocks for synthesis of polymers. The authors developed a method to convert isohexides into isohexide-diene monomers which are amenable to acyclic diene metathesis (ADMET) polymerization. ADMET polymerization of isohexidediene monomers using Grubbs first and second generation catalysts is reported in the work and polymers with molecular weights in the range $800-13800 \mathrm{~g} / \mathrm{mol}$ were successfully synthesized.

The article by Wadgaonkar and co-workers ${ }^{4}$ illustrates a strategy for exploitation of cashew nut shell liquid (CNSL) - a by-product of the cashew nut processing industry and a non-edible oil - as a starting material for synthesis of a partially biobased aromatic diamine monomer containing a pendent pentadecyl chain. The diamine monomer was employed for synthesis of organo-soluble polyimides exhibiting satisfactory thermal properties. The utility of aromatic polyimides possessing pendent pentadecyl chains as an alignment layer in liquid crystal display devices was demonstrated.

The article by Shanmuganathan and co-workers ${ }^{5}$ deals with melanin, which is an interesting biopolymer exhibiting a broad range of properties including photoprotection, free radical scavenging, metal chelation, photoconductivity and antimicrobial behavior. However, the chemical heterogeneity and intractable nature of melanin has so far limited its processability. The authors made an interesting observation that commercially available $40 \mathrm{wt} \%$ tetrabutyl ammonium hydroxide (TBAH) could solvate both natural and synthetic melanins and the dissolution could be made faster with microwave irradiation. Since onium hydroxides including TBAH are known to dissolve cellulose by disrupting the strong hydrogen-bonded network in cellulose, this opens up opportunities to solution-blend the two biopolymers and realize a range of biocomposite materials and properties.

The article by Lochab and co-workers ${ }^{6}$ deals with the utility of cardanol, which is obtained from CNSL, for the development of useful products. The authors demonstrated applicability of blends of cardanol-based benzoxazine and bisphenol-A-based benzoxazine reinforced with nano-alumina as solventless adhesive for stainless steel.

As a guest editor, I would like to thank all the contributors for submitting their new research and the reviewers for ensuring a high standard of the published work.

\section{REFERENCES}

1. Krishnamurthy M, Murugan P, Murali A et al. (2017) 'Click' polymer of carbon nanotubes for superhydrophobic glass and leather. Green Materials 5(2): 46-52, http://dx.doi.org/10.1680/jgrma.17.00001.

2. Pentela N, Ayyappan VG, Krishnamurthy M et al. (2017) A comparative study of $\mathrm{pH}$-responsive microcapsules from different nanocomposites. Green Materials 5(2): 53-62, http://dx.doi.org/10. 1680/jgrma.16.00023. 
3. Rajput BS, Lekshmy KG, Menon SK and Chikkali SH (2017) Synthesis of isohexide-di(ether-ene)s and ADMET polymerization. Green Materials 5(2): 63-73, http://dx.doi.org/10.1680/jgrma.16.00017.

4. Shingte RD, Tawade BV and Wadgaonkar PP (2017) Partially biobased processable polyimides based on aromatic diamine derived from cardanol. Green Materials 5(2): 74-84, http://dx.doi.org/10.1680/jgrma.17.00010.
5. Ram F, Pimpalkar NK, Shete AP and Shanmuganathan K (2017) Solution-processed cellulose/melanin films and fibers. Green Materials 5(2): 85-93, http://dx.doi.org/10.1680/jgrma.17.00003.

6. Monisha, Shukla S and Lochab B (2017) Nanoparticles as curing and adhesive aid for biobased and petrobased polybenzoxazines. Green Materials 5(2): 94-102, http://dx.doi.org/10.1680/jgrma.17.00004. 